\title{
Article \\ Landscape of Spinal Muscular Atrophy Newborn Screening in the United States: 2018-2021
}

\author{
Kshea Hale *, Jelili Ojodu and Sikha Singh
}

Association of Public Health Laboratories, Silver Spring, MD 20910, USA; jelili.ojodu@aphl.org (J.O.); sikha.singh@aphl.org (S.S.)

* Correspondence: kshea.hale@aphl.org; Tel.: +1-240-485-3842

\begin{abstract}
Newborn screening (NBS) programs identify newborns at increased risk for genetic disorders, linking these newborns to timely intervention and potentially life-saving treatment. In the United States, the Health and Human Services (HHS) Advisory Committee on Heritable Disorders in Newborns and Children (ACHDNC) recommends the disorders for state NBS programs to screen. ACHDNC updated the Recommended Uniform Screening Panel to include Spinal Muscular Atrophy (SMA) in July 2018. As of June 2021, 34 state NBS programs had fully implemented SMA newborn screening, and at least 8 programs were pursuing implementation. This article will review current SMA screening processes, considerations, challenges, and status.
\end{abstract}

Keywords: newborn screening; spinal muscular atrophy; new disorders implementation

Citation: Hale, K.; Ojodu, J.; Singh, S Landscape of Spinal Muscular Atrophy Newborn Screening in the United States: 2018-2021. Int. J. Neonatal Screen. 2021, 7, 33. https:// doi.org/10.3390/ijns7030033

Academic Editors: Denise M. Kay and Anne Marie Comeau

Received: 21 May 2021

Accepted: 16 June 2021

Published: 24 June 2021

Publisher's Note: MDPI stays neutral with regard to jurisdictional claims in published maps and institutional affiliations.

Copyright: (c) 2021 by the authors. Licensee MDPI, Basel, Switzerland. This article is an open access article distributed under the terms and conditions of the Creative Commons Attribution (CC BY) license (https:// creativecommons.org/licenses/by/ $4.0 /)$.

\section{Introduction}

Newborn screening (NBS) is a state-implemented public health program intended to identify newborns at increased risk of certain genetic disorders. Some disorders, if undetected and left untreated or detected later within the life course, might cause mild to severe disability and/or premature death for the individual. Through the timely implementation of the newborn screening process, infants detected with these disorders may receive early interventions, potentially reducing short-and long-term adverse health outcomes and improving their overall quality of life. The Health and Human Services (HHS) Advisory Committee on Heritable Disorders in Newborns and Children (ACHDNC) recommends the disorders for state NBS programs to screen [1]. The approved disorders are included on the Recommended Uniform Screening Panel (RUSP), with state newborn screening programs screening for at least 30 of 35 core disorders on the RUSP as of June 2021 [2]. The RUSP was updated to include Spinal Muscular Atrophy (SMA) in July 2018.

Approximately 1 in every 11,000 babies are born with SMA in the United States each year [3]. However, the incidence rate varies by state as established during the evidence review process during the deliberation of whether to add SMA to the RUSP [4]. Initial screening studies in New York revealed a lower birth prevalence (1 in 21,000 as of February 2020) than the published 1 in 11,000 estimated from clinical detection [5]. Globally, few and small studies have been performed, with estimated incidence of SMA in pan-Europe as 1 in 3900 to 1 in 16,000 [6]. As additional global screening results are made available, surveillance estimates will become more precise. The Association of Public Health Laboratories' (APHL) NewSTEPs Data Repository collects information on confirmed cases detected by newborn screening in the US for all disorders annually. They report that at least 45 cases of SMA were detected by newborn screening for the years 2018-2021, with 34 states offering population screening as of June 2021.

As one of the leading genetic causes of mortality for children under the age of 2 years, SMA is a group of genetic disorders that affects the motor neurons in the body. It is primarily caused by defects or mutations in the survival motor neuron 1 (SMN 1) gene. The SMN 1 gene provides instructions for producing the survival motor neuron (SMN) 
protein, which is essential for the maintenance of the motor neurons located in the spinal cord and brainstem [7]. Motor neurons control essential voluntary muscular movement such as crawling, walking, chewing, swallowing, speaking, and breathing. SMA results in the loss of those motor neurons, leading to progressive muscle weakness and atrophy.

The exact course of the disorder and severity of symptoms differs by SMA type and age of onset. There are five types of SMA. Type 0 and type 1 are the most severe and may result in death in early infancy [8]. Individuals with type 2 may survive into adolescence or early adulthood, and those diagnosed with type 3 or type 4 may have a normal life expectancy [9]. Early risk assessment through newborn screening is important to improve long-term outcomes. When SMA is diagnosed and treated early, it is possible for patients to achieve motor developmental milestones [10].

\section{SMA Screening Method}

The exon 7 deletion in the SMN1 gene identifies approximately 95\% of newborns with SMA. All $(n=34)$ newborn screening programs currently screening for SMA utilize a real-time PCR (qPCR) first-tier methodology to detect the deletion of exon 7 in SMN1, as seen in Table 1, and further elaborated in Appendix A. Some programs implement a digital drop PCR or a reverse-transcriptase (RT) PCR second-tier methodology to determine the SMN2 copy number as well $(n=8)$, while other programs repeat the first-tier methodology on the original dried blood spot on the next day (a confirmation duplicate). Five states offer a three-tier, high-throughput screening algorithm [11]. Not all programs implement a second-tier screen, reflexing the newborn screening risk assessment results to a clinical laboratory. Screening algorithms are determined at the state level, taking into consideration feasibility of the screen, demographics, and laboratory capabilities. A majority of NBS programs $(n=25)$ currently screening for SMA also multiplex the screening of SMA with severe combined immunodeficiency (SCID), a disorder that was added to the RUSP in 2010, and that all states have been screening for since at least 2018 [12].

Table 1. Summary of spinal muscular atrophy newborn screening methodologies in the United States, June 2021 (state specific details in Appendix A).

\begin{tabular}{cc}
\hline SMA Screening Methodologies & \# of States \\
\hline Multiplex with SCID & 25 \\
\hline First-tier SMA screen using teal-time PCR for detection of homozygous deletion of exon 7 in SMN1 & 34 \\
\hline First- and second-tier SMA screen & 8 \\
\hline First-, second-, and third-tier SMA screen & 5 \\
\hline
\end{tabular}

\section{SMA Implementation Process and Screening Considerations}

When pursuing full population screening of SMA, there are several phases of implementation, which vary by state, that NBS programs must complete and that impact how long a state may take to achieve population screening. A breakdown of these phases is found in Figure 1. While many of the key activities such as developing a budget, purchasing equipment, and integrating testing into current workflow will occur across all states, the duration and burden of these activities are dependent on parameters such as the size of a state, demographics, hours of operation, fees, number of screens performed, methodologies used for screening, etc. For example, while many programs increase the newborn screening fee when adding disorders to their state panels, others do not.

As newborn screening programs prepare for and enter into the second phase (laboratory, follow-up, and information technology readiness) of implementation, there are several factors NBS programs need to consider to ensure readiness to screen for SMA. A summary of SMA laboratory and follow-up screening considerations and questions is elaborated in Table 2. 
Phase 1:
Authority/Approval to
Screen

- Obtain approval from Advisory Committee

- Obtain spending authority

- Obtain approval to initiate pilot testing

- Obtain regulatory changes to increase fee

Phase 2.

Laboratory, Follow-up, and Information

Technology Readiness

- Select the screening methodology

infrastructure for testing

- Hire additional staff (if needed)

applicable)
-Identify equipment needed and ensure adequate space and physical

-Develop and validate assay for first-tier test (and second-tier test if

-Develop follow-up algorithms and Standard Operating Procedures (SOPs)

-Validate changes to the Laboratory Information Management Systems (LIMS) and re-test as needed

-Validate changes to the electronic results protocol and re-test as needed

-Evaluate Continunity of Operations (COOP) needs specific to addition of new disorder

-Identify and modify family, provider, and public education materials for State

- Develop fact sheets

-Distribute educational materials

- Notify partners of "go-live" date

-Implement pilot population testing (if applicable)

-Implement statewide screening (including follow-up, reporting, and education) for all newborns

- Assess and readjust testing process based on what was learned from statewide screening

- Continually track performance metrics
Live/Assessing Implementation

Process

Figure 1. Phases of implementation for new disorders in newborn screening [13]. 
Table 2. Laboratory and follow-up screening considerations and questions for SMA.

\begin{tabular}{|c|}
\hline Laboratory Considerations \\
\hline $\begin{array}{l}\text { What screening method should be utilized? } \\
\text { - } \quad \text { Single-plex or multiplex } \\
\text { - } \quad \text { Single or multi-tier assays }\end{array}$ \\
\hline What will be the cutoff value and reference gene? \\
\hline What reference materials to use in order to calibrate instrumentation? \\
\hline What material should be utilized for daily positive quality control (QC), and from where do you obtain it? \\
\hline Should the SMN2 copy number be determined within the screening lab? If yes, why and by what method? \\
\hline How will you validate your Laboratory Information Management Systems (LIMS) \\
\hline $\begin{array}{l}\text { Considerations for multiplexing with SCID:Platforms used } \\
\text { - } \quad \text { Cut-off value and validation plan } \\
\text { - What to do in the case if screening fails for one disorder, but not the other? } \\
\text { - } \quad \text { Is there an impact on re-test rate when multiplexing? }\end{array}$ \\
\hline
\end{tabular}

\section{Follow-up Program Considerations}

What are the reporting and follow-up guidelines?

What follow-up data should be collected? Both upon diagnosis and after diagnosis?

Lab results? Clinical findings? Other?

What does surveillance look like for SMA?

How to interpret results of multiplexed assays?

What specialists need to be involved in the follow-up process?

Are specialists determining SMA type based on SMN2 copy numbers and clinical symptoms present at diagnosis?

What wording should be used for the interpretation of normal results/positive results on the NBS report?

Specialist involvement:

- $\quad$ Are cases going directly to neurologists or are they filtered through geneticists?

- How are positive results reported? To a primary care physician? To a specialist? Both?

- $\quad$ Are results called out on weekends?

What is the referral rate? How many (or what \% of) released results to primary care physician/specialist yielded an SMA diagnosis?

\section{State of SMA NBS Implementation}

As of 8 June 2021, 34 state NBS programs are offering population-wide screening for SMA, as seen in Figure 2. This number does not include states conducting pilot testing, frequently performed in states prior to full implementation to validate the screening assay and to evaluate and refine results reporting and communication mechanisms [14]. A least seven additional programs are pursuing implementation for SMA as of June 2021. Approximately $82 \%$ of the 34 NBS programs screening for SMA implemented full population screening within two years of its addition to the RUSP. The number of NBS programs screening for this disorder surpasses the 29 NBS programs currently screening for Pompe disease, which was added to the RUSP in 2015, and the 27 NBS programs screening for mucopolysaccharidosis type I (MPS I) and the 22 newborn screening programs screening for X-linked adrenoleukodystrophy (X-ALD), which were both added in 2016. As indicated in Table 3, the average time to fully implement SMA screening is approximately 24 months, Pompe and MPS I are 40 and 37 months respectively, and X-ALD is 28 months. The most time-intensive activities for each disorder are listed in Table 4. 


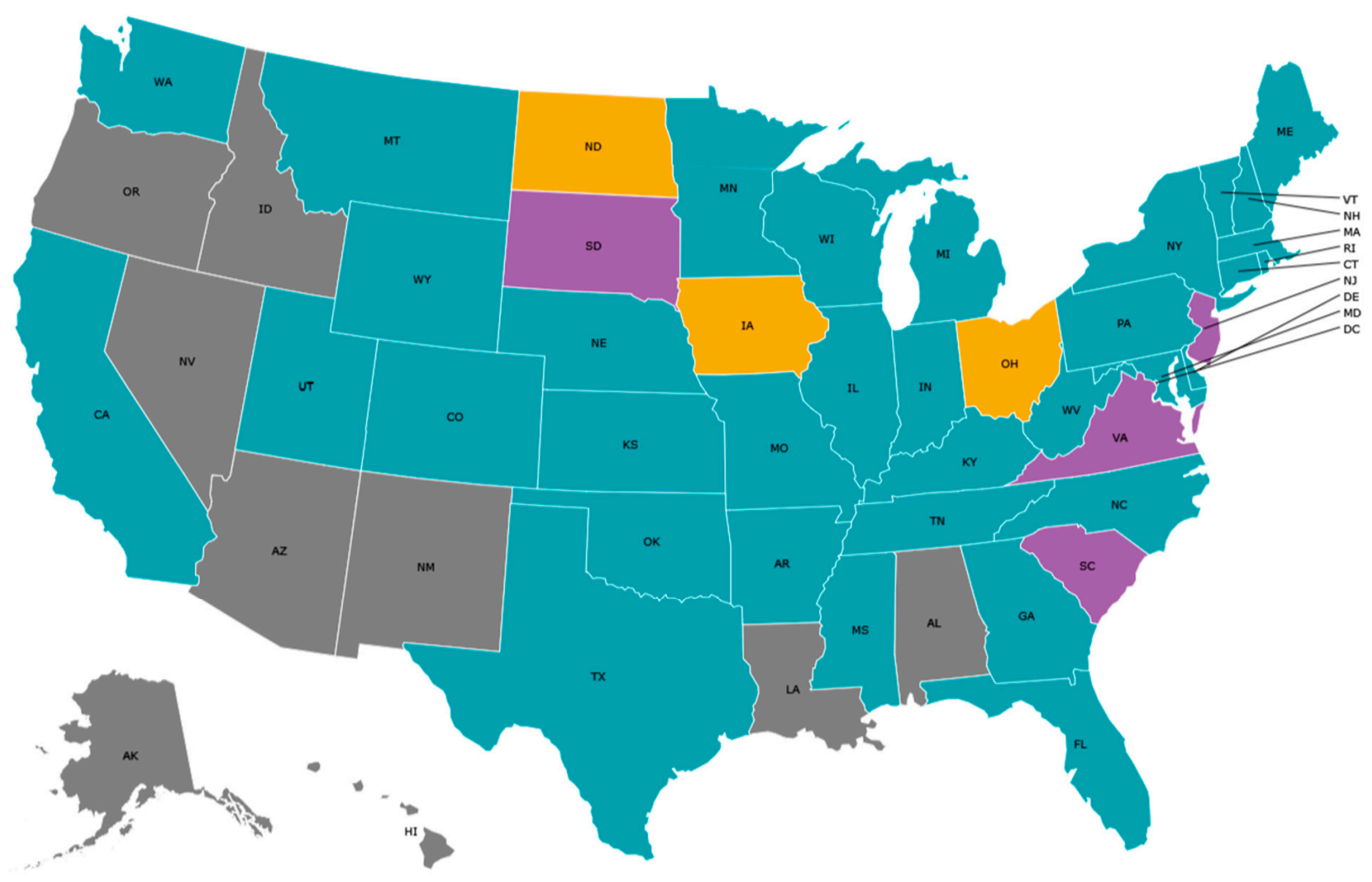

States implementing full population screening

States performing pilot studies

States pursuing implementation

Figure 2. State NBS programs screening for SMA, as of 8 June 2021.

Table 3. Time to full implementation of statewide screening for new disorders. Preliminary results from the NewSTEPs New Disorder Readiness Scale, as of 31 August 2019.

\begin{tabular}{|c|c|c|c|c|c|c|}
\hline Disorder & No. of States & Mean (Months) & Median (Months) & Min (Months) & Max (Months) & Range (Months) \\
\hline Pompe & 11 & 39.64 & 28 & 13 & 99 & 86 \\
\hline MPS I & 13 & 36.92 & 28 & 13 & 75 & 62 \\
\hline X-ALD & 8 & 27.63 & 30.5 & 16 & 36 & 20 \\
\hline SMA & 5 & 24.40 & 20 & 17 & 38 & 21 \\
\hline
\end{tabular}

Table 4. The most time-intensive activity by disorder. Preliminary results from NewSTEPs New Disorder Readiness Scale, as of 31 August 2019.

\begin{tabular}{|c|c|c|}
\hline Disorder & Activity & $\begin{array}{l}\text { Average Time } \\
\text { (Months) }\end{array}$ \\
\hline Pompe & Develop and gain buy-in for STFU protocols for abnormal screens & 15.13 \\
\hline MPS I & Identify screening methodology/assay for first-tier testing & 14.80 \\
\hline X-ALD & Develop/validate assay for second-tier testing & 19.67 \\
\hline SMA & Obtain approval from the state budget authority & 10 \\
\hline
\end{tabular}


The table includes NBS programs that selected "complete" for full implementation. Time is calculated from earliest start date entered by NBS program to the implementation date for statewide screening. Programs that did not provide dates are excluded.

Several state NBS programs have noted that SMA is a relatively simple screen to implement since testing for the presence or absence of a gene yields minimal false-positive results, reducing the need to include a second-tier test [15]. When implementing screening for SMA, most NBS programs multiplexed SMA with SCID (Table 1), the benefit of which is that minimal laboratory staffing and technology changes are needed, and the state may not require a significant fee increase to include SMA on their panels, as compared with other newer disorders that require more complex laboratory, information technology, follow-up, and education considerations [16].

To support state NBS programs as they implemented screening for SMA, the Association of Public Health Laboratories (APHL) Newborn Screening Technical assistance and Evaluation Program (NewSTEPs) provided funding and educational opportunities through a cooperative agreement from the Health Resources and Services Administration (HRSA). State NBS programs utilized funding for SMA screening implementation from NewSTEPs to purchase equipment and supplies, to travel to other state newborn screening laboratories for training, to hire staff, to develop educational resources, and to perform software modifications. State NBS programs applied for funding through a competitive and goals-driven request for proposals (RFP) process. State NBS programs also received direct funding from the Centers for Disease Control and Prevention (CDC) and other newborn screening stakeholders and partners to purchase equipment and supplies, hire staff, and complete other implementation activities.

Programs receiving NewSTEPs funding achieved the following milestones during the funding period: completed on-site training with PerkinElmer to use Janus G3 Mini and Quant Studio DX instruments; received training on Evoya LIMS software; developed a validation plan, completed SMA-SCID validation and test implementation; procured and validated QuantStudio and Pro real-time PCR instruments; added the SMA screening instrument to the LIMS for testing and reporting; identified and procured needed Perkin Elmer SpecimenGate software modifications for SMA implementation; and developed educational materials. To address educational needs, APHL hosted two national webinar series in 2018 and 2019 to discuss SMA implementation with subject matter experts and to support states as they prepare for screening. Speakers discussed the following: SMA screening methodologies and follow-up requirements and processes, state educational strategies, current approved FDA treatments, long-term implications and outcomes of treatment, and physician experiences treating SMA using Spinraza and Zolgensma.

\section{Challenges}

Despite SMA screening being relatively simpler to implement than the other newer disorders added to the RUSP, the timing of implementation in 2020 for the five APHL NewSTEPs funded states coincided with the COVID-19 pandemic, and this confluence of events resulted in several challenges. The specific challenges as described by the funded programs to NewSTEPs via routine discussions and teleconference check-ins are described in Table 5. 
Table 5. Challenges reported by state newborn screening programs receiving NewSTEPs funding to implement SMA newborn screening coinciding with the 2020 global COVID-19 pandemic.

\begin{tabular}{ll}
\hline \multicolumn{1}{c}{ Challenges } & \multicolumn{1}{c}{ Description } \\
\hline Competing Priorities/Shift of Duties & $\begin{array}{l}\text { Several states experienced delays as a result of the COVID-19 pandemic. NBS } \\
\text { program staff from all areas shifted focus from routine duties to address the crisis, } \\
\text { including providing testing for COVID-19. This affected NBS staff, } \\
\text { fiscal/accounting staff, and other support staff in public health laboratories. }\end{array}$ \\
\hline Procurement of Lab Supplies & $\begin{array}{l}\text { The COVID-19 pandemic affected the ability to procure lab supplies needed for } \\
\text { SMA screening, such as pipette tips and reagents. }\end{array}$ \\
\hline External Partners & The COVID-19 pandemic impacted staffing situations with external partners. \\
\hline Legislative Delays & $\begin{array}{l}\text { The COVID-19 pandemic delayed the legislative process, resulting in a delay in } \\
\text { the approval and implementation of SMA screening. }\end{array}$ \\
\hline Malfunctioning of Instrumentation & $\begin{array}{l}\text { One program experienced problems with liquid handling instruments. The } \\
\text { instruments were not functioning correctly due to manufacturing errors. The } \\
\text { program reported that one system had to be replaced and the other modified. The } \\
\text { manufacturer was responsive and spent several days working onsite to fix the } \\
\text { issue. This issue took approximately six weeks to resolve. }\end{array}$ \\
\hline
\end{tabular}

\section{Lessons Learned and Recommendations}

States preparing to screen for SMA should consider the program's capacity and testing needs and begin planning as early as possible to enhance capacity to screen. Planning should include staffing needs, spacing requirements, reagent needs, and instrument capacity to meet SMA screening requirements.

When implementing a new disorder during a pandemic, state NBS programs receiving NewSTEPs funding recommend NBS programs perform the steps listed in Table 6.

Table 6. Recommendations for implementing screening for a new disorder during a pandemic.

\begin{tabular}{cl}
\hline Steps & \multicolumn{1}{c}{ Recommendation } \\
\hline Step 1 & $\begin{array}{l}\text { Order supplies needed with a longer lead time to ensure that manufacturing and } \\
\text { transportation delays do not negatively impact validation timelines. }\end{array}$ \\
\hline Step 2 & $\begin{array}{l}\text { Continue to meet with implementation team composed of laboratory leadership, technical } \\
\text { experts, follow-up leadership, and informatics support staff to ensure that all parties are } \\
\text { informed of validation and regulatory progress. }\end{array}$ \\
\hline Step 3 & Hire additional staff whenever possible before staffing shortages force timeline delays. \\
\hline
\end{tabular}

\section{Conclusions}

The ACHDNC updated the RUSP to include SMA in July 2018. To expand and facilitate screening for SMA, the CDC, APHL NewSTEPs through funding from the Health Resources and Services Administration (HRSA), and other NBS stakeholders provided funding and educational opportunities to US newborn screening programs. Through these funding opportunities, state NBS programs purchased the equipment and supplies needed to perform screening. To provide further support to state programs, APHL hosted several webinars to discuss laboratory, follow-up, and treatment considerations for SMA NBS screening.

As of June 2021, 34 states have implemented SMA screening, despite challenges and delays due to the COVID-19 pandemic. To assist the remaining states that intend to implement SMA screening, APHL will, through its HRSA-funded NewSTEPs program, continue to provide technical support, educational resources, and funding assistance. APHL will also continue to collect, collate, analyze, and disseminate challenges, successes, and lessons learned during the implementation process in an effort to enable continuous quality improvements and to strengthen the body of data around the national landscape for SMA newborn screening. 
Author Contributions: Conceptualization, K.H. and S.S.; methodology, K.H.; formal analysis, K.H.; resources, K.H. and S.S.; data curation, K.H.; writing - original draft preparation, K.H.; writingreview and editing, K.H., J.O. and S.S.; visualization, K.H.; supervision, S.S.; project administration, K.H.; funding acquisition, J.O. All authors have read and agreed to the published version of the manuscript.

Funding: This publication is supported by the Health Resources and Services Administration (HRSA) of the US Department of Health and Human Services (HHS) as part of an award totaling \$1,500,000 with $0 \%$ financed with non-governmental sources. The contents are those of the author(s) and do not necessarily represent the official views of, nor an endorsement, by HRSA, HHS or the US Government. For more information, please visit HRSA.gov.

Data Availability Statement: No new data were created or analyzed in the study. Data sharing is not applicable to this article.

Acknowledgments: The information in this article is based on participation from the APHL NewSTEPs Data Team and NBS programs in the following states: Arkansas, Colorado, Montana, Texas, and Virginia.

Conflicts of Interest: The authors declare no conflict of interest. The funders had no role in the design of the study; in the collection, analyses, or interpretation of data; in the writing of the manuscript, or in the decision to publish the results.

\section{Appendix A}

Table A1. State Screening Methods and Targets for SMA Newborn Screening.

\begin{tabular}{|c|c|c|c|c|c|}
\hline $\begin{array}{c}\text { States Offering } \\
\text { Population NBS for } \\
\text { SMA as of June } 2021 *\end{array}$ & First-Tier Method & First-Tier Target & Second-Tier Method ^ & Second-Tier Target & $\begin{array}{l}\text { Multiplex } \\
\text { with SCID }\end{array}$ \\
\hline Arkansas & qPCR & SMN1 & None & $\mathrm{N} / \mathrm{A}$ & Yes \\
\hline California & qPCR & SMN1 & None & $\mathrm{N} / \mathrm{A}$ & No \\
\hline Colorado & qPCR & SMN1 & None & $\mathrm{N} / \mathrm{A}$ & Yes \\
\hline Connecticut & qPCR & SMN1 & None & $\mathrm{N} / \mathrm{A}$ & Yes \\
\hline Delaware & qPCR & SMN1 & $\begin{array}{l}\text { Multiplex Ligation } \\
\text { PCR Amplification } \\
\text { (MLPA) }\end{array}$ & SMN1and SMN2 & No \\
\hline Florida & qPCR & SMN1 & None & $\mathrm{N} / \mathrm{A}$ & Yes \\
\hline Georgia & qPCR & SMN1 & None & $\mathrm{N} / \mathrm{A}$ & Yes \\
\hline Illinois & qPCR & SMN1 & None & $\mathrm{N} / \mathrm{A}$ & Yes \\
\hline Indiana & qPCR & SMN1 & None & $\mathrm{N} / \mathrm{A}$ & Yes \\
\hline Kansas & qPCR & SMN1 & Digital drop PCR & SMN2 & Yes \\
\hline Kentucky & qPCR & SMN1 & None & $\mathrm{N} / \mathrm{A}$ & Yes \\
\hline Maine ** & qPCR & SMN1 & qPCR & $\begin{array}{l}\text { SMN1exon } 7 \text { (Assay A) AND } \\
\text { SMN1exon 7, SMN1intron } 7 \text { (Assay B) } \\
\text { followed by sequencing as a third tier } \\
\text { if all replicates show absent exon } 7 \\
\text { (Assay A) and one or more replicates } \\
\text { show present Exon } 7 \text { (Assay B) }\end{array}$ & No \\
\hline Maryland & qPCR & SMN1 & None & $\mathrm{N} / \mathrm{A}$ & Yes \\
\hline Massachusetts ** & qPCR & SMN1 & qPCR & $\begin{array}{l}\text { SMN1exon } 7 \text { (Assay A) AND } \\
\text { SMN1exon 7, SMN1intron } 7 \text { (Assay B) } \\
\text { followed by sequencing as a third tier } \\
\text { if all replicates show absent exon } 7 \\
\text { (Assay A) and one or more replicates } \\
\text { show present Exon } 7 \text { (Assay B) }\end{array}$ & No \\
\hline Michigan & qPCR & SMN1 & None & $\mathrm{N} / \mathrm{A}$ & Yes \\
\hline Minnesota & qPCR & SMN1 & None & $\mathrm{N} / \mathrm{A}$ & Yes \\
\hline
\end{tabular}


Table 1. Cont.

\begin{tabular}{|c|c|c|c|c|c|}
\hline $\begin{array}{c}\text { States Offering } \\
\text { Population NBS for } \\
\text { SMA as of June } 2021 \text { * }\end{array}$ & First-Tier Method & First-Tier Target & Second-Tier Method ^ & Second-Tier Target & $\begin{array}{l}\text { Multiplex } \\
\text { with SCID }\end{array}$ \\
\hline Mississippi & qPCR & SMN1 & None & $\mathrm{N} / \mathrm{A}$ & Yes \\
\hline Missouri & qPCR & SMN1 & None & $\mathrm{N} / \mathrm{A}$ & Yes \\
\hline Montana & qPCR & SMN1 & Digital drop PCR & SMN2 & Yes \\
\hline Nebraska & qPCR & SMN1 & None & $\mathrm{N} / \mathrm{A}$ & Yes \\
\hline New Hampshire ** & qPCR & SMN1 & qPCR & $\begin{array}{l}\text { SMN1exon } 7 \text { (Assay A) AND } \\
\text { SMN1exon 7, SMN1intron } 7 \text { (Assay B) } \\
\text { followed by sequencing as a third tier } \\
\text { if all replicates show absent exon } 7 \\
\text { (Assay A) and one or more replicates } \\
\text { show present Exon } 7 \text { (Assay B) }\end{array}$ & No \\
\hline New York & qPCR & SMN1 & Digital drop PCR & SMN2 & Yes \\
\hline North Carolina & qPCR & SMN1 & None & $\mathrm{N} / \mathrm{A}$ & Yes \\
\hline Oklahoma & qPCR & SMN1 & None & N/A & No \\
\hline Pennsylvania & qPCR & SMN1 & $\begin{array}{l}\text { Multiplex Ligation } \\
\text { PCR Amplification } \\
\text { (MLPA) }\end{array}$ & SMN2 & No \\
\hline Rhode Island ** & qPCR & SMN1 & qPCR & $\begin{array}{l}\text { SMN1exon } 7 \text { (Assay A) AND } \\
\text { SMN1exon 7, SMN1intron } 7 \text { (Assay B) } \\
\text { followed by sequencing as a third tier } \\
\text { if all replicates show absent exon } 7 \\
\text { (Assay A) and one or more replicates } \\
\text { show present Exon } 7 \text { (Assay B) }\end{array}$ & No \\
\hline Tennessee & qPCR & SMN1 & $\begin{array}{l}\text { Multiplex Ligation } \\
\text { PCR Amplification } \\
\text { (MLPA) }\end{array}$ & SMN2 & Yes \\
\hline Texas & qPCR & SMN1 & RT-PCR & SMN2 & Yes \\
\hline Utah & qPCR & SMN1 & None & N/A & Yes \\
\hline Vermont $* *$ & qPCR & SMN1 & qPCR & $\begin{array}{l}\text { SMN1exon } 7 \text { (Assay A) AND } \\
\text { SMN1exon 7, SMN1intron } 7 \text { (Assay B) } \\
\text { followed by sequencing as a third tier } \\
\text { if all replicates show absent exon } 7 \\
\text { (Assay A) and one or more replicates } \\
\text { show present Exon } 7 \text { (Assay B) }\end{array}$ & No \\
\hline Washington & qPCR & SMN1 & None & $\mathrm{N} / \mathrm{A}$ & Yes \\
\hline West Virginia & qPCR & SMN1 & None & $\mathrm{N} / \mathrm{A}$ & Yes \\
\hline Wisconsin & qPCR & SMN1 & Digital drop PCR & SMN2 & Yes \\
\hline Wyoming & qPCR & SMN1 & None & $\mathrm{N} / \mathrm{A}$ & Yes \\
\hline
\end{tabular}

* Not all states have a newborn screening laboratory; some newborn screening programs send their dried blood spot specimens to another laboratory. ${ }^{\wedge}$ While many states do not have a second-tier screen for SMA, many will perform a confirmation duplicate by using the same dried blood spot to repeat the qPCR for SMN1 exon 7 deletion the following day. ${ }^{* *}$ Massachusetts has developed, validated and implemented a three-tier, high-throughput algorithm for the detection of SMA-detected infants in Massachusetts, Maine, New Hampshire, Rhode Island, and Vermont [11].

\section{References}

1. Health Resources and Services Administration. Advisory Committee on Heritable Disorders in Newborns and Children. Available online: https:/ / www.hrsa.gov/advisory-committees/heritable-disorders/index.html (accessed on 17 December 2020).

2. Association of Public Health Laboratories. NewSTEPs. Newborn Screening Status for All Disorders. Available online: https://www. newsteps.org/resources/data-visualizations/newborn-screening-status-all-disorders (accessed on 5 May 2021).

3. CureSMA. SMA Overview. Available online: https://www.curesma.org/about-sma/ (accessed on 10 May 2021). 
4. Kemper, A.R.; Ream, M.A.; Lam, K.K. Review of Newborn Screening Implementation for Spinal Muscular Atrophy Final Report. Available online: https://www.hrsa.gov/sites/default/files/hrsa/advisory-committees/heritable-disorders/reportsrecommendations/sma-nbs-implementation-report.pdf (accessed on 8 June 2021).

5. Kay, D.M.; Stevens, C.F.; Parker, A.; Saavedra-Matiz, C.A.; Sack, V.; Chung, W.K.; Chiriboga, C.A.; Engelstad, K.; Laureta, E.; Farooq, O.; et al. Implementation of population-based newborn screening reveals low incidence of spinal muscular atrophy. Genet. Med. 2020, 22, 1296-1302. [CrossRef]

6. Verhaart, I.E.; Robertson, A.; Leary, R.; McMacken, G.; König, K.; Kirschner, J.; Jones, C.C.; Cook, S.F.; Lochmüller, H. A Multisource Approach to Determine SMA Incidence and Research Ready Population. Available online: https://link.springer.com/ content/pdf/10.1007/s00415-017-8549-1.pdf (accessed on 10 June 2021).

7. CureSMA. SMA and Genetics. Available online: https:/ /www.curesma.org/genetics/ (accessed on 10 May 2021).

8. National Center for Biotechnology Information. "PubChem Gene Summary for NCBI Gene 6606" PubChem. Available online: https:/ / pubchem.ncbi.nlm.nih.gov/gene/SMN1/human (accessed on 5 January 2021).

9. National Institutes of Health. National Institute of Neurological Disorders and Stroke Spinal Muscular Atrophy Fact Sheet", NINDS, Publication Date May 2019, NIH Publication No. 19-NS-5597. Available online: https:/ /www.ninds.nih.gov/Disorders/ Patient-Caregiver-Education/Fact-Sheets/Spinal-Muscular-Atrophy-Fact-Sheet (accessed on 10 May 2021).

10. National Organization for Rare Disorders. Rare Disease Database: Spinal Muscular Atrophy. Available online: https:// rarediseases.org/rare-diseases/spinal-muscular-atrophy/ (accessed on 6 January 2021).

11. Hale, J.; Darras, B.; Swoboda, K.; Estrella, E.; Chen, J.; Abbott, M.-A.; Hay, B.; Kumar, B.; Counihan, A.; Gerstel-Thompson, J.; et al. Massachusetts' Findings from Statewide Newborn Screening for Spinal Muscular Atrophy. Int. J. Neonatal Screen. 2021, 7, 26. [CrossRef] [PubMed]

12. Dangouloff, T.; Servais, L. Clinical Evidence Supporting Early Treatment of Patients with Spinal Muscular Atrophy: Current Perspectives. Ther. Clin. Risk Manag. 2019, ume 15, 1153-1161. [CrossRef]

13. Association of Public Health Laboratories. NewSTEPs New Disorder Readiness Scale. Available online: https://www.newsteps. org/sites/default/files/newdisorderreadinessstool_May2021_.pdf (accessed on 30 April 2021).

14. Pass, K.; Green, N.S.; Lorey, F.; Sherwin, J.; Comeau, A.M. Pilot programs in newborn screening. Ment. Retard. Dev. Disabil. Res. Rev. 2006, 12, 293-300. [CrossRef] [PubMed]

15. Kemper, A.R.; Lam, K.K. Newborn Screening for Spinal Muscular Atrophy Phase I: Update of the Evidence Review. Available online: https://www.hrsa.gov/sites/default/files/hrsa/advisory-committees/heritable-disorders/meetings/20170803/kemper.pdf (accessed on 8 June 2021).

16. Hale, K.; Kellar-Guenther, Y.; McKasson, S.; Singh, S.; Ojodu, J. Expanding Newborn Screening for Pompe Disease in the United States: The NewSTEPs New Disorders Implementation Project, a Resource for New Disorder Implementation. Int. J. Neonatal Screen. 2020, 6, 48. [CrossRef] 